\title{
The Effectiveness of Information Technology (IT) Competence in Business Partnerships
}

\author{
Haroun Alryalat ${ }^{*}$ \\ Dean, College of Information Technology, Ajman University, Ajman, UAE \\ *Corresponding author: h.alryalat@ajman.ac.ae
}

\begin{abstract}
The main responsibility of Information Technology (IT) in business is to acquire, implement and maintain technology investments, which belonged within the Information Systems. In order to achieve successful IT planning and implementation, shared knowledge becomes an important enabler of the alignment of business and IT objectives. This research evaluates how cross-functional competence in business and IT people provides the basis for effective partnership to develop. The objective is to conceptually define and empirically measure the variables of IT competence in business managers and of business competence in IT professionals, and test the measurements for validity and reliability. A Simple Percentage Method, chi-square tests, Tables and weighted average were used to get clear picture of analysis with results showing how both IT knowledge and IT experience are instrumental in defining IT competence of business people. The results of these showed that IT service delivery dimensions, IT system dimensions (quality, delivery, trustworthy and management) and IT core characteristics have statistical significant influence on effective IT competences among IT business people and IT cognitive dimensions which included knowledge, skills and experience.
\end{abstract}

Keywords: IT competence, IT in business, business partnership, business managers and IT professionals

Cite This Article: Haroun Alryalat, "The Effectiveness of Information Technology (IT) Competence in Business Partnerships.” American Journal of Systems and Software, vol. 5, no. 1 (2017): 1-8. doi: 10.12691/ajss-5-1-1.

\section{Introduction}

The major duty of IT is to obtain and establish systems of technology which exist within Information Sectors. IT competence in simple terms is the ability of an entity, corporate or human, to obtain and activate IT systems and, with the aid of acquired knowledge and skills, to use them in complex and diversified situations [1].

IT competence is also the ability to use IT knowledge, skills and experience to effectively carry out specific tasks of a business kind. Reference [2] narrowed down these IT competencies to IT knowledge, IT skills, and personal IT expertise and characteristic IT values. Reference [3] seeks to differentiate IT qualification from IT competence. The former is simply the academic IT requirements for a given job while the latter is a human resource attribute which usually leads to productivity.

IT implementation is impossible without shared knowledge especially as this enables an alignment of IT and business objectives [4]. IT competence can also have pre-conditions which [5] refers to as IT competence antecedents. These include socialization in IT, work introduction in IT, consultancy in IT, environmental characteristics involving IT and work experience required in IT.

There is also a five IT competence model quoted by a group of World Bank IT experts which identifies the factors that aid effective partnership in IT business [6]. These include IT task competence, IT professional competence, IT administrative competence and IT ethical competence. Reference [3] also identifies five attributes that guarantee success in IT system as: IT system quality, information quality, IT system quality, service delivery quality, IT system use satisfaction and IT net benefits.

To properly define the competence of individual and corporate businesses in the area of IT, there is a need for IT knowledge, skills, personal IT expertise and IT values. There is however, an emergence of new perspectives on how business partnerships with people could be influenced by IT competence. This is a major part of the researcher's work in this study which seeks to measure those variables of IT competence in managers of business as well as the variables amongst IT professionals of business competence. It also evaluates how a crossfunctional competence could feed and sustain effective partnership.

\subsection{Research Objectives}

The research provides a conceptual definition of the variables of IT competencies in business managers and of business competencies in IT professionals. It then evaluates the necessity of cross-functional IT competencies amongst IT consumers and users and how these aids effective partnership. The specific research objectives are:

(a) To identify the empirical variables involved in IT competencies especially as they concern IT business.

(b) To test how valid and reliable the measurements of these variables are in reference to IT competence of business managers and IT professionals. 
(c) To establish just how much of IT competence in IT business management is influenced by the IT variables.

(d) To determine whether or not there exists a relationship between IT variables and competence in IT professionalism and to also measure this relationship.

\subsection{Research Questions}

The questions formulated by the study are:

(a) What are the factors of Information Technology that define and measure IT competence in business?

(b) How reliable and valid are the IT variables in measuring the IT competence of IT professionals and business managers?

(c) How do the IT variables affect the competence of IT professionals in business management?

(d) Does a relationship exist between these variables and IT competence in IT professionalism and what is the nature of this relationship?

\subsection{Research Hypotheses}

The following research hypotheses were derived from research questions (b), (c) and (d) above:

\subsubsection{Hypotheses a}

The validity and reliability of the IT variables is in question when measuring IT competence of business managers and IT professionals. This hypotheses is derived from the research question (b) above.

\subsubsection{Hypotheses b}

There is no significant influence of the IT variables on IT competence in business management. This hypotheses is derived from the research question (c) above.

\subsubsection{Hypotheses c}

The IT variables have no significant relationship with IT competence in IT professionalism. This hypotheses is derived from the research question (d) above.

\section{Methodology}

\subsection{Research Design}

The research will adopt a quantitative survey design which, as explained in [7], helps in collecting data which reveal attitudes, perceptions, views and opinions from certain respondents as it relates to the study. This data usually comes in numerical form and when systematically analyzed helps to address the outlined objectives of the study while providing inferences that would be drawn into conclusions.

\subsection{Study Variables}

The three sets of variables adopted by this study are response variable (dependent variable), explanatory variables (independent variables) and intervening variables (confounding variables).
The Dependent Variable (DV) refers to an overall rating of IT competence. Whereas, the Independent Variables (IVs) include: knowledge level of IT, IT skills, expertise level, IT values, information quality, quality of IT system, quality of service delivery, management of the IT system and IT net benefits. The intervening (Confounding) Variables (CVs) are characterized by socio-demographic factors which include age, gender, education level, duration of IT usage and the socioeconomic status of IT professionals and IT managers. Demographic variables age, gender, and ethnicity along with academic variables were analyzed in [8].

\subsection{Sampling Procedure}

The primary target of this research were IT managers and professionals in the United Arab Emirates. 150 to 250 individuals were sampled for this study and a simple random sampling was adopted to select the 220 IT managers and professionals. This system usually allows for any individual in the population to have an equal chance of being selected to be part of the study sample [9] and it also helps to save time and resources while accurately addressing research questions with inferences [10]. 202 of the 220 sample units of IT business managers and professionals completed and returned the online questionnaires which represented a 91.8\% turn up rate.

\subsection{Collection of Data}

The study adopted an online web-designed questionnaire as its research instrument. The questionnaire also helped in providing information about the target population and information for reaching valid generalizations. The online questionnaires were divided into five sections:

(a) This section provided information about the personal socio-demographic factors of the respondents.

(b) This was concerned with IT factors that help measure IT competence.

(c) Here, information was provided on how the IT variables measure IT competence validly.

(d) The questionnaire also revealed the influence of the IT variables on overall IT competence in IT business management.

(e) Questions were also included on the connection between the IT variables and overall IT competence in IT professionals.

\subsection{Procedure for Data Analysis}

The data was entered into the Statistics software package interface (SPSS), having been first sorted and organized to allow for effective analysis. Data on sociodemography was analyzed with the aid of tables, graphical methods, distribution percentages and cross tabulations.

Meanwhile, the data, which related to the research objectives, was analyzed with the aid of descriptive statistics and correlation analysis to determine the relationship between IT variables and competence in IT professionals and managers. To analyze the connection between the IT variables and overall IT competence, the study adopted the Chi-square test value and its p-values and odds ratio (OR). The general conclusions of this study were reached by interpreting this data analysis. 


\section{Interpretation of Results}

Here, we look at the results of data analysis which are divided into the following sections: reliability and validity tests, analysis of socio-demographic factors, analysis of data concerning the research objectives and summary of results.

\subsection{Tests on Validity and Reliability}

We used principal component analysis and Cronbach's alpha test to check how valid and reliable the collected data was. These reliability and validity checks are displayed in the Table 1.
Table 1 shows that the component loadings of IT competence variables are greater than 0.47 . What this primarily shows is that seeing the variables of IT competence in this study are above 0.4 , and then they are significantly reliable and valid. References [11] and [12] expounded on this when they said that a factor loading is significant when it is about 0.4 and very significant when more than 0.7 .

The Table 1 also shows that the Cronbach's alpha for Overall IT competence was 0.699 and most of the variables of IT competence showed their Cronbach's alpha as greater than 0.6 . It is safe then to conclude that data collected by the survey tools were valid and reliable [7].

Table 1. Principal component loadings of reliability and validity tests

\begin{tabular}{|c|c|c|c|c|c|c|}
\hline Factor & 1 & 2 & 3 & 4 & 5 & 6 \\
\hline IT knowledge & .869 & & & & & \\
\hline IT skills & .793 & & & & & \\
\hline IT experience & .563 & & & & & \\
\hline Characteristic IT values & & .766 & & & & \\
\hline Characteristic information quality & & .603 & & & & \\
\hline Characteristic expertise quality & & .563 & & & & \\
\hline IT system quality & & & .959 & & & \\
\hline IT system Delivery & & & 481 & & & \\
\hline IT system trustworthy & & & .621 & & & \\
\hline IT system management & & & .541 & & & \\
\hline IT service quality & & & & .820 & & \\
\hline IT service delivery quality & & & & -.463 & & \\
\hline IT service quality & & & & .479 & & \\
\hline IT net profitability & & & & & .530 & \\
\hline IT net benefits & & & & & 649 & \\
\hline IT Compliance for IT Professionals & & & & & & .823 \\
\hline IT Compliance for IT Managers & & & & & & 624 \\
\hline IT Compliance Trust & & & & & & .541 \\
\hline IT Compliance Performance & & & & & & .471 \\
\hline \% Variance explained & 32.9 & 25.7 & 19.2 & 14.6 & 6.3 & 1.3 \\
\hline Cronbach's alpha $(\alpha)$ & 0.781 & 0.813 & 0.682 & 0.598 & 0.711 & 0.699 \\
\hline
\end{tabular}

Table 2. Frequency distribution and descriptive statistics

\begin{tabular}{|c|c|c|c|c|c|}
\hline Factor & attribute & Frequency & Percent \% & Mean & Std deviation \\
\hline \multirow{3}{*}{ Gender } & Male & 110 & 54.5 & \multirow{3}{*}{1.46} & \multirow{3}{*}{.499} \\
\hline & Female & 92 & 45.5 & & \\
\hline & Total & 202 & 100.0 & & \\
\hline \multirow{5}{*}{ Age } & $21-30$ & 34 & 16.8 & \multirow{5}{*}{42.65} & \multirow{5}{*}{1.03} \\
\hline & $31-40$ & 73 & 36.1 & & \\
\hline & $41-50$ & 48 & 23.8 & & \\
\hline & $50+$ & 47 & 23.3 & & \\
\hline & Total & 202 & 100.0 & & \\
\hline \multirow{4}{*}{ Education level } & High school & 42 & 20.8 & \multirow{4}{*}{2.23} & \multirow{4}{*}{1.00} \\
\hline & Tertiary & 94 & 46.5 & & \\
\hline & Degree & 66 & 32.7 & & \\
\hline & Total & 202 & 100.0 & & \\
\hline \multirow{5}{*}{ work experience } & $0-5$ & 60 & 29.7 & \multirow{5}{*}{12.65} & \multirow{5}{*}{.723} \\
\hline & $6-10$ & 59 & 29.2 & & \\
\hline & $11-15$ & 59 & 29.2 & & \\
\hline & $16+$ & 24 & 11.9 & & \\
\hline & Total & 202 & 100.0 & & \\
\hline \multirow{4}{*}{ Socio-economic status } & Low & 36 & 17.8 & \multirow{4}{*}{2.5} & \multirow{4}{*}{1.134} \\
\hline & Middle & 86 & 42.6 & & \\
\hline & High & 80 & 39.6 & & \\
\hline & Total & 212 & 100.0 & & \\
\hline
\end{tabular}




\subsection{Personal Demographic Data}

We made use of descriptive statistics and frequency tables to organize the data on socio-demography. In the below table, you will find the frequency distribution and summary of mean and standard deviation of the five socio-demographic factors which made up this study. Table 2 shows the frequency distribution and descriptive statics.

Table 2 reveals a relative male percentage of $54.5 \%$ and a female percentage of $44.5 \%$ among the IT users who make up the respondents. There is also an obvious gender disparity in the usage of IT as gender has a mean of 1.46 and standard deviation of 0.499. This is also illustrated in the pie chart in the Figure 1 below.

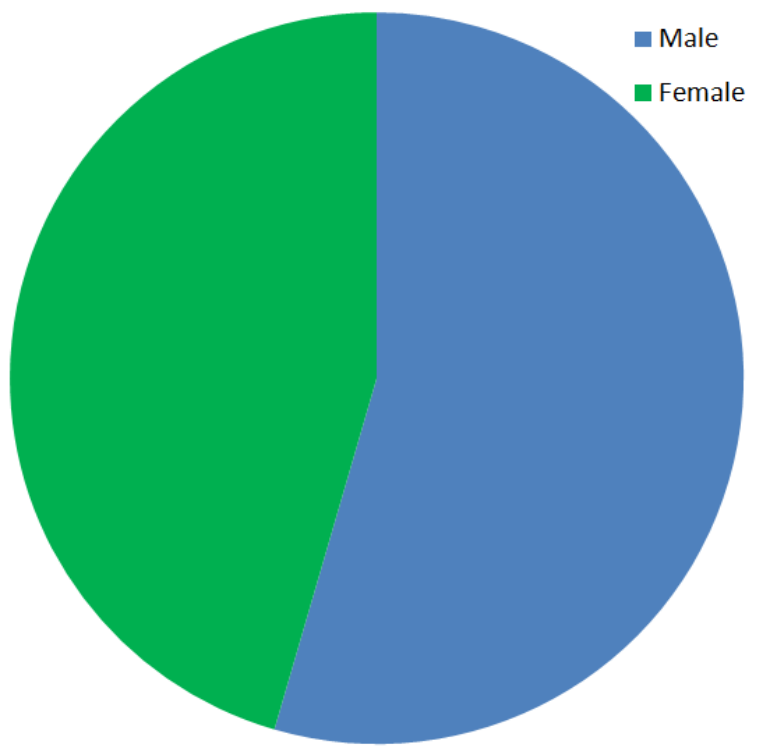

Figure 1. Forward single pass experimental set-up for evaluating EDFA performance

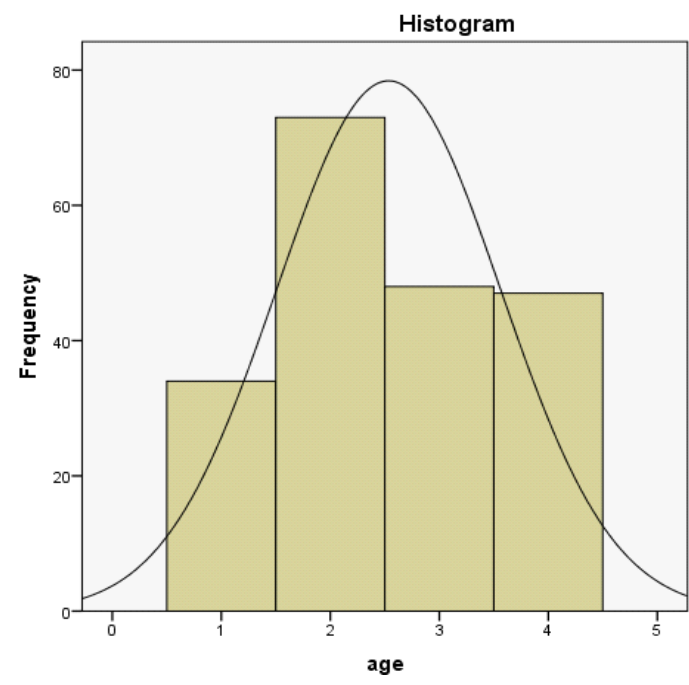

Figure 2. Histogram showing age distribution

It is also evident from Table 2 that the model age bracket was 31-40 years with a relative frequency of $36.1 \%$. Following this is $41-50$ years range, which had a percentage of $23.8 \%$. The 50 years and older were the third having a percentage of $23.3 \%$ and finally $21-30$ years had a percentage of $16.8 \%$. The respondents also had a mean age of 42.65 with a standard deviation of 1.03 . The age distribution as displayed in Figure 2 is almost normally distributed.

The study also aimed at establishing the IT working experience of the respondents.

It was discovered that the majority came from those who had worked for 0-5 years with a relative frequency of $29.7 \%$. This was then followed by $6-10$ and $11-15$ years who both had $29.2 \%$ and a minority of those above 16years at $11.9 \%$. This experience distribution is shown in the graph of Figure 3.

Results collated on the factor of socio-economic status revealed that $42.6 \%$ of IT users were of middle level socio-economic status, $39.6 \%$ had high socio-economic status and those of low socio-economic status were at a minority percentage of $17.8 \%$.

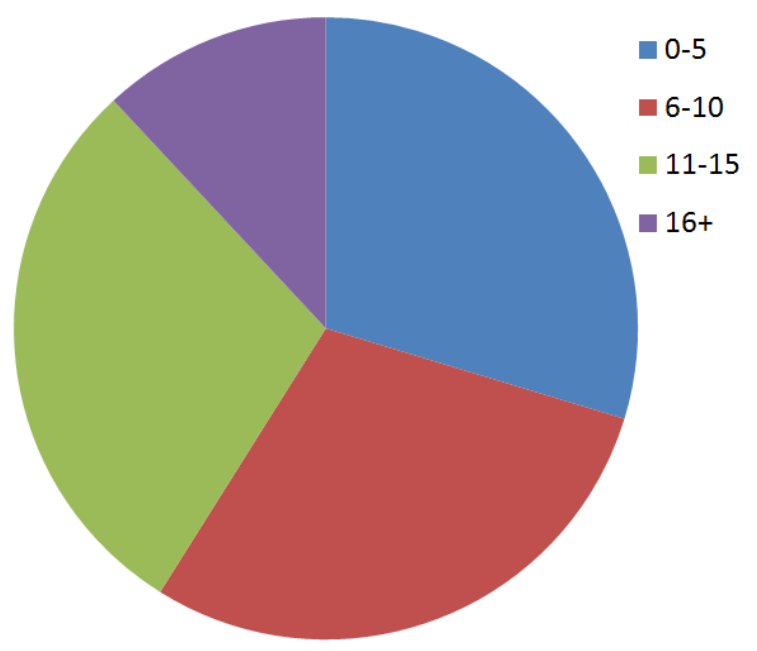

Figure 3. Experience distribution Pie graph

On the educational level of the respondents, majority (46.5\%) had tertiary (Certificate \& Diploma) education, $32.7 \%$ had degree level education and High school education was $20.8 \%$. This is further illustrated in the bar graph of Figure 4.

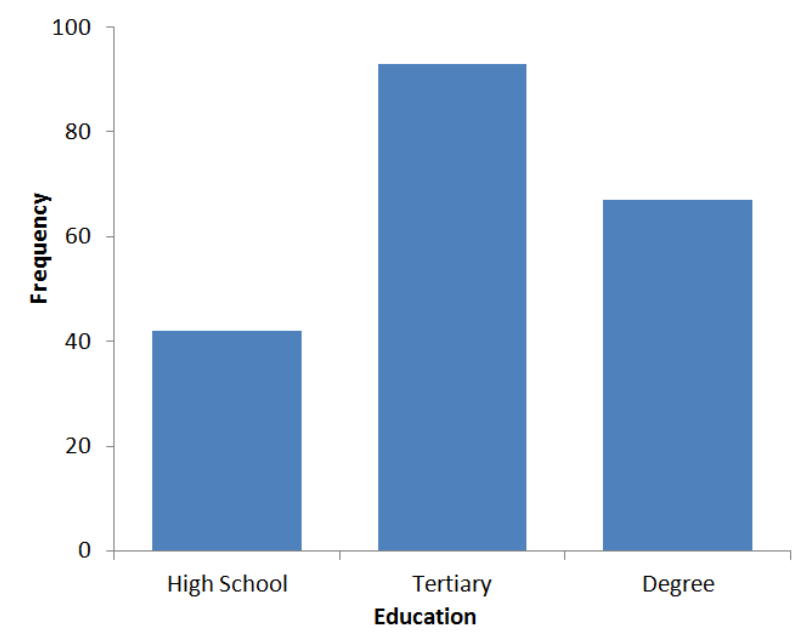

Figure 4. Bar graph showing education level distribution

\subsection{How Valid and Reliable are IT Variables Concerning IT Competence}

Correlation tests were used to analyze and determine how valid and reliable the IT variables were concerning 
the competence of IT business managers. The correlation coefficients were also tested to determine the factors that determine this validity and reliability in IT competence. This correlation analysis of IT variables against the IT competence is given in Table 3.

What the results show is that there was significant connection between IT independent variables and IT competences. The fact that the correlation between IT system dimensions and IT competences was placed at 0.607 shows a relatively strong connection between IT competences and the IT system. In similar correlations, the results revealed; between IT competences and the IT core characteristics ( $\mathrm{r}=0.327)$, IT competences and the IT service delivery dimensions $(\mathrm{r}=0.581)$, IT competences and the IT benefit dimensions ( $\mathrm{r}=0.628)$, IT competences and the IT cognitive dimensions with ( $\mathrm{r}=0.691)$.

The significant correlations between IT competences and the independent IT variable show that using the independent IT variables to measure IT competence of business managers and IT professionals is valid and reliable [13].

\subsection{The Influence of IT Variables on Overall IT Competence}

We used the cross tabulations and Chi-square values to analyze the influence of the IT variables on overall IT competence in IT business management. The Chi-square values and their importance were also tested to determine the significant IT factors which influence the IT competence of business managers.

Table 4 results reveal that the Chi-square tests between IT competences and all the IT independent variables except IT benefits were significant. Also obvious is the fact that the IT system dimensions significantly influenced
IT competence $(\chi 2=10.049, \mathrm{p}=0.002)$. This is also the case with IT core characteristics which influenced IT competences significantly $(\chi 2=7.052, \mathrm{p}=0.008)$. Similarly, the IT service delivery dimensions also had significant influence on IT competences $(\chi 2=16.774, \mathrm{p}=0.000)$. Lastly, all the IT cognitive dimensions were also shown to have influenced IT competences $(\chi 2=9.450, \mathrm{p}=0.002)$. However, there was no influence on the IT competences by IT benefit dimensions $(\chi 2=0.005, \mathrm{p}=0.943)$.

\subsection{Relationship between the IT Independent Variables and Overall IT Competence}

The Chi-square tests were also used to conduct this analysis alongside the odds ratio [14]. They were used to ascertain the independent IT factors that influence IT competence among IT professionals.

Table 5 gives the Chi-square and Odds ratio analysis of IT independent variables against the IT competence of IT professionals. It can be seen from the table results that the relationship between IT system dimensions and IT professional competences was significant $(\chi 2=29.374$, $\mathrm{p}=0.020)$ and that similar relationships existed between IT service delivery dimensions and IT professional competencies $(\chi 2=31.031, \mathrm{p}=0.001)$, IT cognitive dimensions and IT professional competencies $(\chi 2=43.019, \mathrm{p}=0.000)$.

Meanwhile, the odds ratio shows that IT professional competencies are influenced to be higher by 1.868 times when IT system dimensions are high significantly as compared to when they are low. In similar fashion, IT professional competencies are 2.206 times higher when IT service delivery dimensions are high as compared to when they are low. Lastly, IT professional competences go as high as 2.646 times when IT cognitive dimensions are significantly high as compared to when they are low.

Table 3. Correlation analysis of IT variables against the IT competence. r, correlation coefficient; Sig, Significance; N, sample size

\begin{tabular}{|c|c|c|c|c|c|c|c|}
\hline & & IT Competence & IT System & IT Characteristics & IT Service & IT benefits & IT Cognitive \\
\hline \multirow{3}{*}{ IT Competence } & $\mathrm{r}$ & 1 & $.607^{* *}$ & $.327^{* *}$ & $.581^{* *}$ & $.628^{* *}$ & $.691^{* *}$ \\
\hline & Sig. & & .000 & .000 & .000 & .000 & .000 \\
\hline & $\mathrm{N}$ & 202 & 202 & 202 & 202 & 202 & 202 \\
\hline \multirow{3}{*}{ IT System } & $\mathrm{r}$ & $.607^{* *}$ & 1 & $.946^{* *}$ & $.932^{* *}$ & $.547^{* *}$ & $.680^{* *}$ \\
\hline & Sig. & .000 & & .000 & .000 & .000 & .000 \\
\hline & $\mathrm{N}$ & 202 & 202 & 202 & 202 & 202 & 202 \\
\hline \multirow{3}{*}{ IT Characteristics } & $\mathrm{r}$ & $.327^{* *}$ & $.946^{* *}$ & 1 & $.897^{* *}$ & $.443^{* *}$ & $.572^{* *}$ \\
\hline & Sig. & .000 & .000 & & .000 & .000 & .000 \\
\hline & $\mathrm{N}$ & 202 & 202 & 202 & 202 & 202 & 202 \\
\hline \multirow{3}{*}{ IT Service } & $r$ & $.581^{* *}$ & $.932^{* *}$ & $.897^{* *}$ & 1 & $.731^{* *}$ & $.847^{* *}$ \\
\hline & Sig. & .000 & .000 & .000 & & .000 & .000 \\
\hline & $\mathrm{N}$ & 202 & 202 & 202 & 202 & 202 & 202 \\
\hline \multirow{3}{*}{ IT benefits } & $r$ & $.628^{* *}$ & $.547^{* *}$ & $.443^{* *}$ & $.731^{* *}$ & 1 & $.837^{* *}$ \\
\hline & Sig. & .000 & .000 & .000 & .000 & & .000 \\
\hline & $\mathrm{N}$ & 202 & 202 & 202 & 202 & 202 & 202 \\
\hline \multirow{3}{*}{ IT Knowledge } & $\mathrm{r}$ & $.691^{* *}$ & $.680^{* *}$ & $.572^{* *}$ & $.847^{* *}$ & $.837^{* *}$ & 1 \\
\hline & Sig. & .000 & .000 & .000 & .000 & .000 & \\
\hline & $\mathrm{N}$ & 202 & 202 & 202 & 202 & 202 & 202 \\
\hline
\end{tabular}


Table 4. Cross tabulation and Chi-square analysis of IT independent variables against the IT competence of IT business managers. $\chi^{2}=$ Chisquare value; Sig, Significance

\begin{tabular}{|c|c|c|c|c|c|c|c|}
\hline & & & \multicolumn{2}{|c|}{ IT system } & \multirow{2}{*}{ Total } & \multicolumn{2}{|c|}{ Chi-Square test } \\
\hline & & & Low & High & & $\chi^{2}$ & Sig. \\
\hline \multirow{6}{*}{ IT Competence } & \multirow{2}{*}{ Low } & Count & 40 & 16 & 56 & & \\
\hline & & $\%$ of Total & $19.8 \%$ & $7.9 \%$ & $27.7 \%$ & & \\
\hline & \multirow{2}{*}{ High } & Count & 68 & 78 & 146 & $10.049^{\mathrm{a}}$ & .002 \\
\hline & & $\%$ of Total & $33.7 \%$ & $38.6 \%$ & $72.3 \%$ & & \\
\hline & \multirow{2}{*}{ Total } & Count & 108 & 94 & 202 & & \\
\hline & & $\%$ of Total & $53.5 \%$ & $46.5 \%$ & $100.0 \%$ & & \\
\hline \multirow{6}{*}{ IT Competence } & & & \multicolumn{2}{|c|}{ IT Characteristics } & \multirow{2}{*}{ Total } & & \\
\hline & & & Low & High & & & \\
\hline & \multirow{2}{*}{ Low } & Count & 37 & 19 & 56 & & \\
\hline & & $\%$ of Total & $18.3 \%$ & $9.4 \%$ & $27.7 \%$ & $7.052^{\mathrm{a}}$ & .008 \\
\hline & \multirow{2}{*}{ High } & Count & 66 & 80 & 146 & & \\
\hline & & $\%$ of Total & $32.7 \%$ & $39.6 \%$ & $72.3 \%$ & & \\
\hline \multirow{2}{*}{\multicolumn{2}{|c|}{ Total }} & Count & 103 & 99 & 202 & & \\
\hline & & $\%$ of Total & $51.0 \%$ & $49.0 \%$ & $100.0 \%$ & & \\
\hline \multirow{6}{*}{ IT Competence } & & & \multicolumn{2}{|c|}{ IT Services } & \multirow{2}{*}{ Total } & & \\
\hline & & & Low & High & & & \\
\hline & \multirow{2}{*}{ Low } & Count & 44 & 12 & 56 & & \\
\hline & & $\%$ of Total & $21.8 \%$ & $5.9 \%$ & $27.7 \%$ & $16.774^{\mathrm{a}}$ & .000 \\
\hline & \multirow{2}{*}{ High } & Count & 68 & 78 & 146 & & \\
\hline & & $\%$ of Total & $33.7 \%$ & $38.6 \%$ & $72.3 \%$ & & \\
\hline \multirow{2}{*}{\multicolumn{2}{|c|}{ Total }} & Count & 112 & 90 & 202 & & \\
\hline & & $\%$ of Total & $55.4 \%$ & $44.6 \%$ & $100.0 \%$ & & \\
\hline \multirow{6}{*}{ IT Competence } & & & \multicolumn{2}{|c|}{ IT Cognitive } & \multirow{2}{*}{ Total } & & \\
\hline & & & Low & High & & & \\
\hline & \multirow{2}{*}{ Low } & Count & 49 & 7 & 56 & & \\
\hline & & $\%$ of Total & $24.3 \%$ & $3.5 \%$ & $27.7 \%$ & $9.450^{\mathrm{a}}$ & .002 \\
\hline & \multirow{2}{*}{ High } & Count & 96 & 50 & 146 & & \\
\hline & & $\%$ of Total & $47.5 \%$ & $24.8 \%$ & $72.3 \%$ & & \\
\hline \multirow{2}{*}{\multicolumn{2}{|c|}{ Total }} & Count & 145 & 57 & 202 & & \\
\hline & & $\%$ of Total & $71.8 \%$ & $28.2 \%$ & $100.0 \%$ & & \\
\hline & & & & & Total & & \\
\hline & & & Low & High & & & \\
\hline IT Compotong & Low & Count & 31 & 25 & 56 & & \\
\hline il competence & LOW & $\%$ of Total & $15.3 \%$ & $12.4 \%$ & $27.7 \%$ & $.005^{\mathrm{a}}$ & .943 \\
\hline & His & Count & 80 & 66 & 146 & & \\
\hline & MIIII & $\%$ of Total & $39.6 \%$ & $32.7 \%$ & $72.3 \%$ & & \\
\hline Totol 20 & & Count & 111 & 91 & 202 & & \\
\hline 10tal & & $\%$ of Total & $55.0 \%$ & $45.0 \%$ & $100.0 \%$ & & \\
\hline
\end{tabular}

Table 5. Chi-square and Odds ratio analysis of IT independent variables against the IT competence of IT professionals. $\chi 2$, Chi-square value; df, degrees of freedom; Sig, Significance

\begin{tabular}{|c|c|c|c|c|}
\hline \multirow{2}{*}{ IT Factor against IT competence relationship } & \multicolumn{3}{|c|}{ Chi-Square test } & \multirow{2}{*}{ Odds Ratio (High / Low) } \\
\cline { 2 - 4 } & $\chi 2$ & $\mathrm{df}$ & Sig. & 1.868 \\
\hline IT system & $29.374^{\mathrm{a}}$ & 8 & .020 & 1.010 \\
\hline IT Characteristics & $22.232^{\mathrm{a}}$ & 8 & .102 & 2.206 \\
\hline IT Services & $31.031^{\mathrm{a}}$ & 8 & .001 & 2.646 \\
\hline IT Cognitive & $43.019^{\mathrm{a}}$ & 8 & .000 & 1.023 \\
\hline IT Benefits & $3.667^{\mathrm{a}}$ & 8 & .886 & \\
\hline
\end{tabular}


Table 6. Research summary. $\alpha$, Cronbach's alpha value; $r$, correlation coefficient; $\chi 2$, Chi-square value; $\mathbf{p}$, p-value/Significance; OR, Odds Ratio

\begin{tabular}{|c|c|c|}
\hline & Research question & Result \\
\hline (a) & $\begin{array}{l}\text { Which IT factors define and measure IT } \\
\text { competence in IT business? }\end{array}$ & $\begin{array}{l}\text { As determined by principal component analysis and Cronbach's alpha, these are: } \\
\text { (a) IT knowledge, skills and experience }(\alpha=0.781) \text {, } \\
\text { (b) Core IT characteristic values }(\alpha=0.813) \\
\text { (c) IT system quality and delivery }(\alpha=0.682) \\
\text { (d) IT net benefits }(\alpha=0.711) \text { and } \\
\text { (e) IT service delivery }(\alpha=0.598) \text {. }\end{array}$ \\
\hline (b) & $\begin{array}{l}\text { How valid and reliable are the IT variables } \\
\text { in defining and measuring IT competences? }\end{array}$ & $\begin{array}{l}\text { Relying on correlation analysis, the valid and reliable IT variables in measuring IT competence } \\
\text { were: } \\
\text { (a) IT system dimensions with }(\mathrm{r}=0.607, \mathrm{p}=0.000) \text {. } \\
\text { (b) IT core characteristics }(\mathrm{r}=0.327 \& \mathrm{p}=0.000) \\
\text { (c) IT service delivery dimensions }(\mathrm{r}=0.581 \& 0.000) \\
\text { (d) IT benefit dimensions }(\mathrm{r}=0.628 \& \mathrm{p}=0.000) \\
\text { (e) IT cognitive dimensions with }(\mathrm{r}=0.691 \& \mathrm{p}=0.000)\end{array}$ \\
\hline (c) & $\begin{array}{l}\text { To what extent do the IT variables influence } \\
\text { overall IT competence? }\end{array}$ & $\begin{array}{l}\text { Relying on Chi-square tests and cross tabulation, the following IT variables were shown to have } \\
\text { influence on overall IT competence: } \\
\text { (a) IT system dimensions with }(\chi 2=10.049, \mathrm{p}=0.002) \\
\text { (b) IT core characteristics }(\chi 2=7.052, \mathrm{p}=0.008) \\
\text { (c) The IT service delivery dimensions }(\chi 2=16.774, \mathrm{p}=0.000) \\
\text { (d) IT cognitive dimensions }(\chi 2=9.450, \mathrm{p}=0.002) \text {. }\end{array}$ \\
\hline (d) & $\begin{array}{l}\text { Is there a relationship between IT variables } \\
\text { and overall IT competence? }\end{array}$ & $\begin{array}{l}\text { The Chi-square and odds ratio tests revealed the below IT variables as having significant } \\
\text { correlation with IT competence: } \\
\text { (a) IT system dimensions }(\chi 2=29.374, \mathrm{OR}=1.868 \& \mathrm{p}=0.020) \\
\text { (b) IT service delivery dimensions }(\chi 2=31.031, \mathrm{OR}=2.206 \& \mathrm{p}=0.001) \\
\text { (c) IT cognitive dimensions with }(\chi 2=43.019, \mathrm{OR}=2.646 \& \mathrm{p}=0.000)\end{array}$ \\
\hline
\end{tabular}

\section{Summary of Results}

The outcome of the research is summarized in the Table 6 which answers the four research question on IT competence.

\section{Research Findings and Conclusion}

The IT variables of competence as revealed in this study have principal component loadings greater than 0.4 and this proves them to be significantly valid and reliable. The principal component analysis also showed that IT knowledge, skills and experience, characteristic IT core values, IT system quality and delivery, IT net benefits and IT service delivery were independent values of IT competence and this was corroborated by the Cronbach's alpha tests.

A gender disparity was also revealed in IT usage amongst study respondents; $54.5 \%$ of male users as against $44.5 \%$ of female users. Meanwhile, 31-40 years was shown as the modal age bracket of IT managers and IT professionals while 21-30 years was the minority age bracket. On the issue of working experience, the majority came from those who had spent $0-5$ years in IT service. Finally, the study revealed that the socio-economic status of the majority of IT users was of the middle level and that more IT managers and professionals had attained the tertiary (Certificate \& Diploma) level of education.

From the study, it could also be concluded that it is valid and reliable to ascertain IT competence using independent IT variables as these appear to have a strong correlation with IT competences.

The study concludes by showing that IT competence of IT managers are influenced by IT system dimensions as well as by IT core characteristics, IT service delivery dimensions and IT cognitive dimensions.
With the aid of odds ratio statistics, the study reached a conclusion that IT competencies go as high as 1.868 times when IT system dimensions are significantly high compared to when they are low. Similarly, IT competencies go up 2.206 times when IT service delivery dimensions are high compared to when they are low and when IT cognitive dimensions are high, they help push IT competencies 2.646 times higher as compared to when they (IT cognitive dimensions) are low.

\section{References}

[1] Svetlik, I., O kompetencah. V: Pezdirc, M. S. (ur.). Kompetence v kadrovski praksi, GV izobraževanje, Ljubljana, 2005, 12-27.

[2] Virtanen, T., "Changing competences of public managers: tensions in commitment," International journal of public sector management, 13 (4). 333-341. 2000.

[3] Kim, S., "Learning goal orientation, formal mentoring, and leadership competence in Information technology. A conceptual model,” Journal of European industrial training, 31 (3). 181-194. 2007.

[4] May, A. S., "Think globally - act locally! Competences for global management," Career development international, 2 (6). 308-311. 2007.

[5] Rappe, C. and Zwick, T., "Developing IT leadership competence of production unit managers,” Journal management development, 26 (4). 312-330. 2007.

[6] World Bank, Building Knowledge Economies: Advanced Strategies for Development, WBI development studies, 2007. [Ebook] Available: http://hdl.handle.net/10986/6853.

[7] Krueger, R. A. and Casey, M. A., Focus groups: A practical guide for applied research, Sage publications, 2014.

[8] Richmond. A., Haroun, A. and Khalid. A, "Interpreting causes of attrition in an information technology (I.T.) undergraduate degree Program within a Gulf State Regional University,” International journals of multidisciplinary research academy, 6 (10). 200-225. 2016.

[9] Mugenda, O.M., Research methods: Quantitative and qualitative approaches, African centre for technology studies, Nairobi, 2003.

[10] Richmond, A., Haroun, A. and Theo, O., "Perspectives for CyberDeterrence: A Quantitative Analysis of Cyber Threats and Attacks 
on Consumers," International journal of innovative research in science, engineering and technology, 5 (7). 1-18. Aug.2016.

[11] Kothari, C. R., Research methodology: Methods and techniques, New Age International, New Delhi, 2004.

[12] Hair, J.F., Anderson, R.E., Tatham, R.L. and Black, W.C. Multivariate data analysis, Prentice-Hall Publishers, Englewood Cliffs, 1998.

[13] Richmond, A. and Boumedyen, S., "A Security analysis to be technology architecture for ministry of regional municipalities and water resources (MRMWR)," International journal of research in social sciences, 6 (1). 1-6. Jan. 2017.

[14] Richmond, A. and Boumedyen, S., "Schemes for distributed computing environment based on cloud computing technology for ministry of regional municipalities and water Resources (MRMWR),” International journal of engineering inventions, 6 (1). 01-06. Jan 2017. 